\title{
CARACTERIZAÇ̃̃o DE AMINOÁCIDOS NA Bertholletia excelsa: VIABILIDADE NUTRICIONAL PARA INCORPORAÇÃO NA DIETA DE FILHOTES DE PEIXE-BOI DA AMAZÔNIA EM CATIVEIRO
}

\author{
Paula de Sousa BARBOSA ${ }^{1 *}$, Olga Lima Tavares MACHADO ${ }^{2}$, Vera Maria Ferreira da SILVA ${ }^{1}$, Geraldo \\ PEREIRA Junior ${ }^{3}$ \& Jucelia da Silva ARAUJO ${ }^{2}$
}

\begin{abstract}
1 Laboratório de Mamíferos aquáticos, Instituto Nacional de Pesquisas da Amazônia. Manaus, Amazonas, Brasil.
2 Laboratório de Química e Função de Proteínas e Peptídeos, Universidade Estadual do Norte Fluminense. Campos dos Goytacazes, Rio de Janeiro, Brasil.

3 Departamento de Produção Animal, Instituto Federal de Educação, Pesquisa e Extensão do Rio de Janeiro. Pinheiral, Rio de Janeiro, Brasil.

*Autor para correspondência: manatee_psbd@ @otmail.com
\end{abstract}

DOI: http://dx.doi.org/10.18571/acbm.151

\section{RESUMO}

A maioria dos filhotes de Trichechus inunguis órfãos que chegam aos centros de pesquisa e reabilitação é lactante. Essa condição dificulta o processo de reabilitação, sendo necessário oferecer uma dieta láctea artificial adequada. Com o intuito de incrementar o teor de aminoácidos no sucedâneo lácteo buscou-se dentre os alimentos habitualmente amazônicos um ingrediente capaz de fornecer os nutrientes necessários para potencializar o sucedâneo utilizado, sendo facilmente adquiro, apresentar alto valor biológico, rápida manipulação, perecibilidade reduzida e baixo custo de obtenção. Dentre os alimentos que preenchem esses pré-requisitos, destaca-se a castanha-do-Brasil. Avaliou-se neste estudo a viabilidade nutricional em termos de aminoácidos da Bertholletia excelsa, para a possível suplementação no sucedâneo lácteo fornecido aos filhotes de peixe-boi da Amazônia em cativeiro. As amêndoas foram descascadas, maceradas e em seguida foi pesado $27 \mathrm{mg}$, digerido em $\mathrm{HCl} 6 \mathrm{M}$, aquecido a $150{ }^{\circ} \mathrm{C}$ por 90 minutos e analisado por Cromatografia Líquida de Alta Eficiência por troca iônica. Os resultados demonstraram uma concentração elevada de aminoácidos não essenciais, dentre eles arginina e ácido glutâmico + glutamina. Os aminoácidos em menor concentração foram prolina, alanina e tirosina. Dentre os aminoácidos essenciais, a valina e a leucina apresentaram as maiores concentrações, entretanto os aminoácidos menos abundantes foram à histidina, isoleucina. Os demais aminoácidos apresentaram teores equivalentes na análise da composição em aminoácidos da castanha. Concluiu-se nesse trabalho que a castanha do Brasil é uma fonte potencial de enriquecimento nutricional na dieta láctea de filhotes de T.inunguis em cativeiro.

Palavras-chave: Bertholletia excelsa; Bioquímica; Alimentação; Sirênios.

\begin{abstract}
Most puppies of Trichechus inunguis orphans that reach the research and rehabilitation centers are lactating. This condition hinders the rehabilitation process, and it is necessary to offer an adequate artificial milk diet. In order to increase the amino acid content in the milk substitute, an ingredient was found to be an ingredient capable of supplying the necessary nutrients to potentiate the substitute used, being easily obtainable, high biological value, fast handling, low and low perishability cost of procurement. Among the foods that fulfill these prerequisites, Brazil nut is outstanding. The nutritional viability in terms of amino acids of Bertholletia excelsa was evaluated in this study for possible supplementation in the milk substitute provided to captive Amazonian manatee pups. The almonds were peeled, macerated and then weighed $27 \mathrm{mg}$, digested in $6 \mathrm{M} \mathrm{HCl}$, heated at $150{ }^{\circ} \mathrm{C}$ for 90 minutes and analyzed by High Efficiency Liquid
\end{abstract}


Chromatography by ion exchange. The results demonstrated a high concentration of non-essential amino acids, among them arginine and glutamic acid + glutamine. The amino acids in lower concentration were proline, alanine and tyrosine. Among the essential amino acids, valine and leucine had the highest concentrations, however, the least abundant amino acids were histidine, isoleucine. The other amino acids presented equivalent content in the analysis of the amino acid composition of the nut. It was concluded that Brazil nut is a potential source of nutritional enrichment in the dairy diet of $T$. inunguis pups in captivity.

Keywords: Bertholletia excels; Biochemistry; Feeding; Sirenians.

\section{Introdução}

O peixe-boi da Amazônia Trichechus inunguis (Natterer, 1883) é uma espécie endêmica da bacia amazônica, sendo considerado o menor dentre os sirênios (ROSAS, 1994). A fêmea de T.inunguis tem um único filhote no intervalo de 2,5 a 5 anos, após gestação de aproximadamente 12-14 meses, sendo que o filhote é amamentado por pelo menos dois anos (BEST, 1984).

De acordo com a classificação da União Internacional para a Conservação da Natureza o T. inunguis é considerado espécie vulnerável à extinção (IUCN, 2017). O status de conservação deste mamífero aquático se deve a vários fatores, principalmente à caça comercial no século passado, à baixa taxa reprodutiva da espécie e a perda de habitat (ROSAS, 1994). Apesar de esta espécie ser, no Brasil, oficialmente protegida por lei desde 1967 (Lei de Proteção a Fauna, N ${ }^{\circ}$ 5197, de 03 de janeiro de 1967; Portaria N 3481 de 31 de maio de 1973 e Portaria $\mathrm{N}^{\circ} .011$, de 21 de fevereiro de 1986), ela continua sendo caçada tanto para subsistência dos povos ribeirinhos da Amazônia quanto para o mercado ilegal de carne que ocorre nas feiras municipais.

Via de regra, fêmeas com filhotes são mais vulneráveis à caça, pois as crias necessitam vir com maior frequência à superfície para respirar (BEST et al., 1982). Com a mãe caçada, o filhote órfão não tem condições de sobreviver sozinho na natureza. Os filhotes resgatados são encaminhados aos criadouros conservacionistas ou centros de pesquisa, e recebem os cuidados necessários à sua sobrevivência.

Nos centros de reabilitação os filhotes de peixes-boi órfãos geralmente chegam muito estressados, apresentando diferentes condições de saúde e em diferentes faixas etárias, sendo a grande maioria ainda lactente. Isto torna a reabilitação ainda mais complexa, pois nesta fase da vida uma nutrição adequada é fundamental, onde todos os nutrientes de que o filhote precisa está presente em um alimento essencial a sua vida, o leite materno. Desta forma, pesquisas vêm sendo realizadas ao longo do tempo com o objetivo de ofertar uma dieta láctea que seja adequada aos filhotes de T.inunguis suprindo suas demandas nutricionais e garantindo a integridade fisiológica, lhes oferecendo o suporte necessário para um desenvolvimento pleno.

Contudo, estudos avaliando mamífero terrestre ao longo da primeira semana de lactação, mostra que o ganho de peso vivo inicial influencia positivamente o desempenho do animal durante todo o período de lactação, sendo que comprometimentos de desenvolvimento inicial não são compensados em outras fases da vida (MATEO et al., 2008). Deste modo, a elaboração de dietas completas em termos de aminoácidos para filhotes de peixe-boi da Amazônia órfãos em cativeiro são importantes no intuito de proporcionar a estes animais um desenvolvimento inicial adequado, fazendo com que eles expressem todo o seu potencial genético.

Com o intuito de incrementar o teor de aminoácidos no sucedâneo lácteo fornecido aos filhotes órfãos de peixe-boi da Amazônia, buscou-se dentre os alimentos habitualmente amazônicos um ingrediente capaz de fornecer os nutrientes necessários para potencializar o sucedâneo utilizado, além de ser facilmente adquiro, apresentar alto valor biológico, rápida manipulação, perecibilidade reduzida e baixo custo de obtenção. 
Dentre os alimentos que preenchem esses pré-requisitos, observou-se que a castanha-doBrasil (Bertholletia excelsa), uma semente oleaginosa abundante em toda a extensão da região Amazônica, é conhecida por apresentar um elevado teor proteico (15 a 20\% da sua composição) sendo estas de alto valor biológico (SUN et al., 1987). Neste contexto o objetivo deste trabalho foi avaliar viabilidade nutricional em termos de aminoácidos da Bertholletia excelsa, para a possível suplementação no sucedâneo lácteo fornecido aos filhotes de peixe-boi da Amazônia em cativeiro.

\section{Material e métodos}

O experimento foi realizado na Central de Sequenciamento de Proteínas do Laboratório de Química e Função de Proteínas e Peptídeos-LQFPP da Universidade Estadual do Norte Fluminense Darcy Ribeiro - UENF.

Para este experimento, as sementes foram adquiridas nas feiras da cidade de Manaus ainda com casca para garantir a máxima preservação de suas características nutricionais. As amêndoas foram delicadamente descascadas, pesadas e maceradas.

\subsection{Análise da composição de aminoácidos}

\subsection{Clivagem}

As amostras ( $27 \mathrm{mg}$ ) foram diluídas em $50 \mu \mathrm{L}$ de $\mathrm{HCl} 6 \mathrm{M}$ (Sigma Aldrich). Esta solução foi depositada em frasco de vidro React vial@, vedado e colocado em banho de areia por cerca de 90 minutos a uma temperatura de $150^{\circ} \mathrm{C}$. Em seguida as amostras foram secas sob gás nitrogênio e ressuspendidas em $1000 \mu \mathrm{L}$ solução de $\mathrm{HCl}$ 0,001 M, filtrada e armazenada para posterior análise. As amostras digeridas e ressuspendidas, foram diluídas na proporção 1:50 em $\mathrm{HCl}$ $0,001 \mathrm{M}$ e $20 \mu \mathrm{L}$ desta solução foram aplicados no analisador de aminoácidos. Para a análise empregou-se a cromatografia de troca iônica e derivatização pós-coluna com orto-fitaldialdeído (OPA), conforme descrição a seguir.

\subsection{Análise cromatográfica}

As amostras foram analisadas em cromatógrafo líquido de alta eficiência (CLAE) Shimadzu LC-10AD seguindo o manual de instruções do equipamento (SHIMADZU CORPORATION, 1993), equipado com coluna de troca catiônica Shimadzu Shim-pack Amino$\mathrm{Na}$ de 4,6 x $100 \mathrm{~mm}$ e detector de fluorescência.

Para eluição foi empregado um gradiente crescente de $\mathrm{pH}$, constituído por tampão citrato de sódio, kit Shimadzu, tipo NA, formado pelas soluções AA-MA, AA- MB, AA-MC, cuja composição química é descrita na tabela 1. Os aminoácidos foram detectados por fluorescência de excitação/emissão de $350 \mathrm{~nm}$ e $450 \mathrm{~nm}$, respectivamente, utilizando derivatização pós-coluna em uma solução 0,08\% de ortoftaldialdeído (OPA) em tampão Carbonato de sódio. A temperatura da coluna foi de $60^{\circ} \mathrm{C}$, o fluxo de eluição $0,5 \mathrm{~mL} / \mathrm{min}$. O tempo de corrida foi de $45 \mathrm{~min}$.

A coluna foi padronizada com uma mistura de aminoácidos para hidrólise de proteínas (Sigma Aldrich A9781) constituída de ácido aspártico +asparagina (Asx), ácido glutâmico + glutamina (Glx), treonina (Thr), prolina (Pro), glicina (Gly), alanina (Ala), valina (Val), leucina (Leu), tirosina (Tyr), fenilalanina (Phe), lisina (Lys), arginina (Arg), serina (Ser), isoleucina (Ile). Foram aplicados no HPLC 500 pmoles de cada aminoácido. 
Tabela 1: Composição química das soluções (fase móvel) usadas para eluição dos aminoácidos.

\begin{tabular}{c|c|ccc}
\hline Coluções & Unidade & AA-MA & AA-MB & AA-MC \\
\hline Normalidade & - & 0,20 & 0,60 & 0,20 \\
pH & - & 3,20 & 10,00 & (nao ajustar o pH) \\
Citrato de sódio & $(\mathrm{g})$ & 58,80 & 58,80 & - \\
Hidroxido de sódio & $(\mathrm{g})$ & - & - & 4,00 \\
Ácido bórico & $(\mathrm{g})$ & - & 12,40 & - \\
Etanol & $(\mathrm{mL})$ & 210,00 & - & - \\
Ácido perclórico $(60 \%)$ & $(\mathrm{mL})$ & 50,00 & - & - \\
NaOH & $(\mathrm{mL})$ & - & 30,00 & 500 \\
Volume final & $(\mathrm{mL})$ & 3,000 & 1,000 & \\
\hline
\end{tabular}

\section{Resultados}

A análise de aminoácidos na $B$. excelsa neste estudo apresentou uma concentração elevada de aminoácidos não essenciais, dentre eles arginina $(19,46 \%)$ e ácido glutâmico + glutamina $(19,37 \%)$. Os aminoácidos em menor concentração neste estudo foram prolina $(2,01 \%)$, alanina $(2,53 \%)$ e tirosina $(2,10 \%)$.

Em relação aos aminoácidos essenciais, a valina $(6,30 \%)$ e a leucina $(5,10 \%)$ apresentaram as maiores concentrações, entretanto os aminoácidos menos abundantes foram a histidina $(3,21 \%)$, isoleucina $(3,04 \%)$. Os demais aminoácidos apresentaram teores equivalentes (a proximadamente 4\%) na análise da composição em aminoácidos da castanha, como descrito na Tabela 2.

Tabela 2: Composição em aminoácidos essenciais e não essenciais de castanhado- Brasil (Bertlholletia excelsa) neste estudo.

\begin{tabular}{cc|cc}
\hline \multicolumn{4}{c}{ Aminoácidos } \\
\hline Essenciais & Média $\pm \mathbf{D P}$ & Não essenciais & Média $\pm \mathbf{D P}$ \\
\hline Phe & $4,71 \pm 1,12$ & Asx & $8,34 \pm 0,67$ \\
His & $3,21 \pm 0,80$ & Ser & $5,25 \pm 1,40$ \\
Lys & $4,53 \pm 0,09$ & Glx & $19,37 \pm 1,04$ \\
Val & $6,30 \pm 1,26$ & Pro & $2,01 \pm 0,29$ \\
Met & $4,27 \pm 0,38$ & Gly & $3,38 \pm 0,64$ \\
Ile & $3,04 \pm 0,96$ & Ala & $2,53 \pm 0,13$ \\
Leu & $5,10 \pm 0,88$ & Tyr & $2,10 \pm 0,45$ \\
Thr & $3,47 \pm 0,43$ & Arg & $19,46 \pm 0,34$ \\
\hline
\end{tabular}

\section{Discussão}

A composição em aminoácidos essenciais da castanha-do-Brasil neste estudo foi semelhante aos verificados por SILVA et al., (2010). Com relação aos aminoácidos não essenciais os resultados corroboram aos descritos por SOUZA \& MENEZES (2004).

No caso de animais com elevada demanda nutricional, como é o caso de mamíferos jovens, os aminoácidos tradicionalmente classificados como "não essenciais", como por exemplo, a glutamina, o ácido glutâmico e a arginina são considerados "aminoácidos funcionais" necessitando serem incrementados na dieta (BRASSE-LAGNEL et al., 2003; YAO et al., 2008). Esses aminoácidos desempenham importantes funções em várias vias metabólicas, no entanto não são sintetizados em quantidades suficientes para atender a máxima demanda exigida para a formação, desenvolvimento e manutenção da saúde vascular e intestinal do indivíduo em desenvolvimento (KIM et al., 2004). 
A arginina é considerada indispensável para o crescimento máximo de mamíferos jovens uma vez que este aminoácido é constituinte primário para a síntese de albumina (LEHNINGER et al., 2014). As albuminas desempenham um papel vital no armazenamento e na regulação das concentrações de diversas substâncias como ácidos graxos, bilirrubina, triptofano, vários íons metálicos, alguns hormônios e inúmeros medicamentos (FOSTER, 1977). Em T.inunguis jovens, mantidos em cativeiro, o teor de albumina sérica é de 4,23 (3,50-5,00) g/dL (SOUSA et al., 2016), sendo que, essa concentração pode estar relacionada com a dieta e com o consumo individual de cada animal (COLARES et al., 2011). Além disso, FLYNN et al (2002), destacam que a arginina desenvolve funções metabólicas cruciais ao desenvolvimento, sendo que a deficiência pode causar retardo do crescimento, disfunção intestinal, além de anormalidades cardiovasculares e pulmonares.

Vale a pena ressaltar que a castanha pode possuir outra vantagem na alimentação desta espécie, uma vez que 69\% de sua composição é formada por ácidos graxos de cadeia longa insaturados e poli-insaturados, são eles: ácido palmítico (C16:0), ácidos esteárico (C18:0), oleico (C18:1), linoleico (C18:2), linolênico (C18:3), araquidônico (C20:0); palmitoléico (C16:1) e mirístico (C14:0). Esses ácidos graxos também foram descritos em análises da composição do leite de peixe-boi marinho Trichechus manatus (ALTIERI et al., 2009).

Além do incremento nutricional a castanha por suas características "sui generis" também pode agregar sabor agradável ao sucedâneo, melhorando a palatabilidade da mistura facilitando a aceitação do filhote ao novo alimento, diminuindo com isso a fase crítica de adaptação ao cativeiro.

Apesar destas características desejáveis, o excesso de castanha na dieta pode ser um fator limitante na sua utilização devido ao teor de selênio $(<50 \mu \mathrm{g} / \mathrm{g})$ contido na semente. Isso ocorre, pois, esse componente pode ligar-se covalentemente a proteínas substituindo os elementos sulfurados, como a metionina e a lisina, por selenometionina e selenolisina causando intoxicação (CHUNHIENG et al., 2004).

Entretanto, SANTOS et al. (2010) avaliando o estado fisiológico de juvenis de tambaqui alimentados com rações contendo níveis de inclusão de castanha-do-Brasil como fonte proteica, concluíram que é possível adicionar até 30\% desta semente em rações para esta espécie, sem comprometer a homeostase fisiológica das mesmas e melhorando consideravelmente o seu valor nutricional em termos de aminoácidos.

Ainda, estudo investigando os efeitos da ingestão da castanha-do- Brasil sobre o perfil lipídico sérico em voluntários saudáveis demonstraram que apesar de apresentar um aumento significativo dos níveis de selênio no plasma 6 horas após a ingestão, uma única porção de castanha-do-brasil (25 gramas) pode melhorar agudamente o perfil lipídico do soro sanguíneo de voluntários saudáveis sem alterar as funções hepático-renal (COLPO et al., 2009).

Os resultados da composição em aminoácidos da castanha-do-Brasil indicam que a utilização deste alimento como um incremento na dieta láctea pode auxiliar no processo de reabilitação de filhotes de peixe-boi da Amazônia lactantes em cativeiro.

\section{Conclusão}

A castanha-do-Brasil demonstrou ser um alimento com potencial para inclusão no sucedâneo lácteo do peixe-boi da Amazônia devido ao seu valor nutricional, principalmente relacionado a composição de aminoácidos não essenciais. Desta forma, a inclusão diária dessas amêndoas na dieta láctea para o peixe-boi da Amazônia pode incrementar o teor nutricional deste alimento, potencializando com isso o desenvolvimento corpóreo destes filhotes, diminuindo os riscos durante a reabilitação no cativeiro. No entanto, sugere-se que estudos estipulando a quantidade e ideal deste alimento, assim como, o desempenho produtivo e conversão alimentar sejam realizados para garantir a máxima eficiência da dieta láctea. 


\section{Agradecimentos}

A agência de fomento do estado do Amazonas - FAPEAM/ Conselho Nacional de Desenvolvimento Científico e Tecnológico pela bolsa de pesquisa. O apoio do Projeto Mamíferos Aquáticos da Amazônia, patrocinado pela Petrobras por meio do Programa Petrobras Socioambiental/AMPA. Ao Laboratório de Química e Função de Proteínas e Peptídeos-LQFPP por meio da Central de Sequenciamento de Proteínas da Universidade estadual do Norte fluminense Darcy Ribeiro - UENF.

\section{Referências}

ALTIERI, B. L.; GODOY, H .T.; SCHERER, R.; MONTANO, G. A. Fatty acid milk composition of a wild Antillean manatee (Trichechus manatus manatus) in Ceará State, Northeast of Brazil. International association for aquatic animal medicine: Conference proceedings. San Antonio, Texas USA.2009.

A Lista Vermelha da UICN de Espécies Ameaçadas. Versão 20172. <www.iucnredlist.org >. Transferido em 28 de setembro de 2017.

BEST, R. C.; RIBEIRO, G.A.; YAMAKOSHI, M. \& DA SILVA, V.M.F. Artificial feeding for unweaned Amazonian manatees (Trichechus inunguis). International Zoo Yearbook, v. 22, p. 263-267, 1982.

BEST, R. The Aquatic Mammals and Reptiles on the Amazon. In: The Amazon. Limnology and landscape ecology of a mighty tropical river and its basi. H. Sioli (editors.). Netherlands; 1984. p. $370-412$.

BRASSE-LAGNEL, C.; FAIRAND, A.; LAVOINNE, A.; HUSSON, A. Glutamine stimulates argininosuccinate synthetase gene expression through O-glycosylation of Sp1 in Caco-2 cells. Journal of Biological Chemistry, v. 278(52), p. 52504-52510, 2003.

CHUNHIENG, T.; PÉTRITIS, K.; ELFAKIR, C.; BROCHIER, J.; GOLI, T.; MONTET, D. Study of Distribution in the Protein Fractions of the Brazil Nut, Betholletia excelsea. Journal Agricultural and Food Chemistry, v. 52(13), p. 4318-4322, 2004.

COLARES, E. P.; COLARES, I. G.; AMARAL, A. D.. Parâmetros Bioquímicos do Sangue do Peixe-boi da Amazônia (Trichechus inunguis, Mammalia: Sirenia). Natural Resources, v.1(2), p. 15-20, 2011.

COLPO, E.; VILANOVA, C.; BRENNER REETZ, L.; DUARTE, M. M. M. F.; FARIAS, I. L. G.; MULLER, E. I.; MULLER, A. L. H.; FLORES, E. M. M..; WAGNER, R..; ROCHAL, J. B. T. A single consumption of high amounts of the Brazil nuts improves lipid profile of healthy volunteers. Journal of Nutrition and Metabolism, p. 1-7, 2013.

FLYNN, N. E.; MEININGER, C. J.; HAYNES, T. E.; WU, G. The metabolic basis of arginine nutrition and pharmacotherapy. Biomed Pharmacother, v. 56: 427-438, 2002.

FOSTER, J. Some aspects of the structure and conformational properties of serum albumin. (Editors): Rosenoer V.M.; Oratz M.; Rothschild M.A. Albumin: Struture, Function and uses; Pergamon Press. 1977. p. 53-84. 
KIM, S.W.; MCPHERSON, R.L.; WU, G. Dietary arginine supplementation enhances the growth of milk-fed young pigs. Nutrient requirements, p. 625-631, 2004.

LEHNINGER, A. L.; COX, N.; KAY, Y. Princípios de bioquímica. 6º edição. Savier. 2014

MATEO, R. D.; WU, G.; MOON, H. K.; CARROL, J. A.; KIM, S. W. Effects of dietary arginine supplementation during gestation and lactation on the performance of lactating primiparous sows and nursing piglets. Journal of Animal Science, v. 86, p. 827-835, 2004.

ROSAS, F. Biology, Conservation and Status of the Amazonian Manatee Trichechus inunguis. Mammal Review, v. 24(2), p. 49- 59, 1994.

SANTOS, M. Q. C.; OISHI, C. A.; PEREIRA-FILHO, M.; LIMA, M. A. C.; ONO, E. A.; AFFONSO, E. G. Physiological response and performance of tambaqui fed with diets supplemented with Amazonian nut. Ciência Rural, v.40, p. 2181-2185, 2010.

SILVA, R. F.; ASCHERI, J. L. R.; SOUZA, J. M. L. Influência do processo de beneficiamento na qualidade de amêndoas de castanha-do-brasil. Ciência e Agrotecnologia, v. 34 (2), p. 445-450, 2010.

SOUZA, M. L.; MENEZES, H. C. Processamento de amêndoa e torta de amêndoa de castanhado-Brasil e farinha de mandioca: Parâmetros de qualidade. Ciência e Tecnologia de Alimentos, v.24(1), p. 120-128, 2004.

SOUSA, I. K. F.; SOUSA, R. S.; AZEVEDO, A. C. P.; CORREA, I. F. C. V.; OLIVEIRA, J. M.; MATOS, S. P.; MORI, C. S.; ORTOLANI, E. L.; ALMOSNY N. R. P. Variáveis hematológicas e bioquímicas de peixe-boi da Amazônia (Trichechus inunguis) jovens. Pesquisa Veterinária Brasileira, v. 36(9), p. 869-873, 2016.

SUN, S. S. M.; ALTENBACH, S. B.; LEUNG, F. W. Properties, biosynthesis and processing of a sulfur-rich protein in Brazil nut (Bertholletia excelsa H.B.K.), European Journal of Biochemistry, v. 162, p. 477-483, 1987.

YAO, K.; YIN, Y. L.; CHU, W. Y.; LIU, Z.; DENG, D.; LI, T.; HUANG, R.; ZHANG, J.; TAN, B.; WANG, W.; WU, G. Dietary arginine supplementation increases mTOR signaling activity in skeletal muscle of neonatal pigs. Journal of Nutrition, v. 138, p. 867-872, 2008. 